\title{
Vocabulary Learning Strategies and Vocabulary Size: Insights from Educational Level and Learner Styles
}

\author{
Alaa Alahmadi ${ }^{\mathrm{a}}$, Christopher Shank ${ }^{\mathrm{a}}$, and Anouschka Foltz \\ ${ }^{a}$ School of Languages, Literatures and Linguistics, Bangor University, \\ Bangor, Gwynedd, UK \\ ${ }^{b}$ Department of English Studies, University of Graz, Graz, Austria \\ https:/doi.org/10.7820/vli.v07.1.alahmadi
}

\begin{abstract}
This study investigates the effect of different vocabulary learning strategies (VLS) as well as different learner styles on vocabulary size in Saudi Arabic-speaking students in higher education. The goals of this study were to examine which VLS undergraduates used more frequently than postgraduates and vice versa, to determine which VLS related positively and significantly to vocabulary size, and to explore individual learner styles and their relationship to vocabulary size. Participants filled in a VLS questionnaire and completed a vocabulary size test. The results indicated that undergraduates tended to use simpler strategies than postgraduates. The strategies of guessing a word's meaning from context and watching television related positively with vocabulary size in both groups. Clustering analysis revealed two learner groups which differed in how frequently they used VLS overall, rather than in terms of which VLS they preferred. Those students who used more VLS overall also had larger vocabulary sizes, irrespective of educational level. We thus found no evidence for differences in individual learner styles in the current groups. We conclude that VLS usage should be encouraged overall, but that the need for instructors to cater to individual vocabulary learning styles may not be warranted.
\end{abstract}

Key words: Vocabulary acquisition; vocabulary learning strategies; vocabulary size; postgraduates; Arabic learners of English.

\section{Background}

In the past three or more decades, the importance of second language (L2) vocabulary learning has gained increased attention. Researchers, teachers and curriculum designers agree that acquiring the vocabulary of a foreign language is important for language learners (Coady, 1997; Gu, 2003; Nation, 1990; Ruutmets, 2005; Schmitt, 1997, 2000). Moreover, language learners seem to acknowledge the significance of vocabulary knowledge, as they usually use dictionaries rather than grammar books (Wilkins, 1972). In the same vein, Wilkins (1972) stated that "without grammar very little can be conveyed, without vocabulary nothing can be conveyed" (p. 110-111). Furthermore, McCarthy (1990) and Shen (2008) argued that language proficiency is heavily 
dependent on individuals' vocabulary knowledge. Indeed, several studies have found a significant and positive correlation between learners' vocabulary size and scores on formal tests of the four language skills: listening, speaking, reading and writing (Koizumi \& In'nami, 2013; Laufer, 1994, 1997; Meara \& Jones, 1988; Stæhr, 2008, 2009).

While vocabulary knowledge plays a vital role in language proficiency, many researchers have argued that vocabulary acquisition is the most challenging feature of learning a foreign language (Milton, 2009; Schmitt, 2000). McCarthy (2001, p. 2) suggests that "vocabulary forms the biggest part of the meaning of any language, and vocabulary is the biggest problem for most learners". To address these difficulties, a number of researchers have developed various strategies to support language learners in their efforts to efficiently acquire vocabulary (Gu, 2003; Oxford, 1990; Read, 1997; Schmitt, 1997).

\subsection{Language Learning Strategies and Vocabulary Learning Strategies}

Language learning strategies (LLS) have received considerable attention since the 1960s (Safian, Malakar, \& Kalajahi, 2014). This reflects the educational shift from focusing on instructors and teaching methods to learners and learning styles (Chamot \& O’Malley, 1987; Fillmore, 1983; Stern, 1975; Wenden, 1982). Schmitt (1997) attributed this educational shift to the general awareness that aptitude is not the only major factor for successful language learning, but that individual learner's strategies may be equally important. As such, researchers have shifted their focus to learners' individual learning approaches and how learners control their learning and language use.

There are various, and sometimes controversial, definitions of LLS in the literature (Oxford, 1990). We follow Cohen's (1998) definition of LLS:

Language learning and language use strategies can be defined as those processes which are consciously selected by learners and which may result in action taken to enhance the learning or use of a second or foreign language, through the storage, retention, recall, and application of information about that language. (p. 4)

While VLS are considered a sub-class of LLS, O’Malley and Chamot (1990) have argued that most LLS are used for accomplishing vocabulary learning tasks. We follow Catalan's (2003) definition of VLS as:

the mechanism used in order to learn vocabulary as well as steps or actions taken by students (a) to find out the meaning of unknown words, (b) to retain them in long-term memory, (c) to recall them at will, and (d) to use them in oral or written mode. (p. 56)

Many vocabulary learning strategies have been proposed in the literature (e.g., Nation, 2001; Schmitt, 1997; Stoffer, 1995). This study uses Schmitt's (1997) comprehensive and frequently cited VLS taxonomy, which integrates key components of Nation's (1990), Oxford's (1990) and Cook and Mayer's (1983) taxonomies. Schmitt's taxonomy (see Figure 1) divides VLS into discovery strategies, 


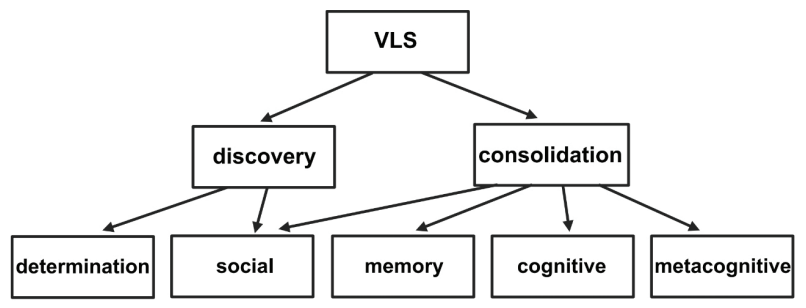

Figure 1. Graphical Overview of Schmitt's (1997) Taxonomy

which are used to learn the meaning of a new word, and consolidation strategies, which are used to remember words once they have been initially learnt. Schmitt's discovery strategies have two sub-strategies: determination strategies and social strategies. Determination strategies aid vocabulary acquisition by providing a set of limited choices from which a word's meaning can be determined, such as using a dictionary or deriving meaning from context. Social strategies support vocabulary attainment by cooperating with others in the acquisition process (Tanyer \& Ozturk, 2014). Consolidation strategies are further subdivided into social (see above), memory, cognitive and metacognitive strategies. Memory strategies refer to learners' mental attempts to link new words with their background knowledge (Schmitt, 1997). Cognitive strategies involve manipulating language materials to enhance the learning process, for example, note-taking, analysis or outlining (Oxford, 2003). Finally, metacognitive strategies may be described as knowledge about learning. This could involve learners' conscious knowledge about how to identify their own learning style preferences, monitoring learning shortcomings and evaluating their learning progress (Oxford, 2003; Schmitt, 1997).

\subsection{The Importance of Vocabulary Knowledge}

Previous studies have shown a statistically significant positive relationship between vocabulary knowledge and language proficiency (e.g., Milton, 2009). Most research concerning this relationship has been conducted within the realm of reading (Stæhr, 2008). A number of researchers have proposed vocabulary sizes necessary to achieve a minimum level of understanding in a foreign language. Milton (2009) indicated that English as a Foreign Language (EFL) learners needed to know at least 3000 words to perform well in basic communicative tasks (Nation, 1990). Proposed thresholds for reading academic and authentic texts range from 5000 words to 9000 word-families (headword plus inflected forms and some derived forms; Al-Masrai \& Milton, 2012; Hirsh \& Nation, 1992; Nation, 2001). Nation (2006) suggested a vocabulary knowledge of 6000 to 7000 word-families to understand spoken discourse. Overall, it is presumed that, regardless of the skill, learners familiar with more words have more opportunities to achieve better comprehension and production of the foreign language.

A number of studies have investigated how English learners' VLS use relates to vocabulary size, using VLS questionnaires in combination with tests that estimate vocabulary knowledge. These studies have yielded rather diverse results. For example, Al Qahtani (2005) conducted a comprehensive analysis of VLS use 
among 455 students from three educational levels (ages 13 through 15, high school and university undergraduate level) in Saudi Arabia and found significant correlations between vocabulary size and guessing the meaning of a word from its structure, monolingual dictionary usage and learners' self-monitoring by listening to their own recordings to detect errors.

Hamzah, Kafipour and Abdullah (2009) have also investigated VLS usage and its relationship with vocabulary size in 125 Iranian second-year undergraduates majoring in Teaching English as a Foreign Language (TEFL). In their study, significant and positive correlations were found between vocabulary knowledge and performing a physical action while learning a new word, communicating with native speakers and watching English media.

Alsaif (2011) explored the use of VLS and their relationship with vocabulary size among 111 Saudi male students representing four public schools and distinctive school levels (from level 7 to level 11). The findings highlighted a positive relationship between vocabulary knowledge and associating new words with known synonyms and antonyms and guessing the words' meanings from context.

Finally, Tanyer \& Ozturk (2014) examined 80 Turkish university students in years 1 through 4 of their undergraduate studies, who were majoring in English Language Teaching (ELT). A hierarchical multiple regression analysis revealed that social, cognitive and metacognitive strategies significantly influenced participants' vocabulary knowledge and explained 6.5\%, 5.3\% and 5.2\%, respectively, of the variability in vocabulary size.

\subsection{Individual Learner Styles}

Individual learning styles refer to the idea that learners differ in terms of the approach of teaching or learning that is optimal for them (Pashler, McDaniel, Rohrer \& Bjork, 2008). The concept of learning styles has gained much attention recently (e.g., Kozhevnikov, 2007; Sternberg, Grigorenko, \& Zhang, 2008), which has led learning styles proponents to design learning styles models or schemes, such as Kolb's $(1984,1985)$ Learning Styles Inventory. These schemes can assist instructors in highlighting their students' learning styles. Based on this, teachers can also adapt their instruction to these individual learner styles. For example, Kolb's (1985) learning styles differentiate between a preference for active experimentation and reflective observation. In terms of VLS, this would reflect a preference for strategies that involve active participation compared to observation or for strategies that involve speaking compared to listening.

However, whether or not using individual learning styles as a means to improve learning outcomes is effective has been debated in the literature. Ormrod (2008) suggests that "some cognitive styles and dispositions do seem to influence how and what students learn" (p. 160). Kojic-Sabo and Lightbown (1999) explored how English as a Second Language (ESL) and EFL learners' styles relate to vocabulary knowledge. They used clustering analysis to group participants in terms of learner styles and found eight different learner groups. Their results suggest that learners who make more use of VLS have larger vocabulary knowledge. In addition, the two most successful groups in terms of vocabulary knowledge 
were characterised by a large amount of time spent on using strategies and a high amount of strategy use outside of the classroom. Similarly, Pashler et al.'s (2008) review of learning styles suggests that there was no adequate evidence to justify the prominent role of individual learning styles in general educational practice.

\subsection{Current Study}

The purpose of this study is to shed light on the VLS usage of students in higher education. We will consider the VLS usage of undergraduates who are completing their degree in Saudi Arabia and postgraduates studying in an L2 environment, as this is a common educational path for Saudi students. Universities in Englishspeaking countries are accepting many international postgraduates into their programmes. These students are typically required to have reached a certain level of English proficiency, typically a score of 5.5 or above in the International English Language Testing System (IELTS), before they can begin their studies. In addition, these students need to build up their vocabulary competence in order to participate effectively within their academic disciplines in the L2. Postgraduates in the L2 environment have different opportunities to practice their vocabulary than students in the first language (L1) environment. In particular, they have more opportunities to learn vocabulary through social strategies, such as communicating with and listening to native speakers. This study investigates which VLS postgraduates use significantly more frequently than undergraduates and vice versa and which VLS are related to participants' vocabulary size. Furthermore, the study explores whether we can identify any individual learner styles and how different learner styles relate to vocabulary size. The latter analysis follows Kojic-Sabo and Lightbown (1999) in using cluster analysis to explore whether there are any distinct VLS profiles that could contribute to participants' vocabulary knowledge. To the best of our knowledge, very few previous studies have attempted to explore individual learner styles in terms of L2 vocabulary acquisition, and this is the first study that considers VLS usage of postgraduate learners. In summary, the study attempts to answer the following research questions (RQs):

1. Which of the VLS relate significantly to vocabulary size in both groups?

2. Are there any strategies that postgraduates use significantly more or less frequently than undergraduates?

3. Are there distinct VLS profiles or learning styles across the sample and, if so, which of these contribute to vocabulary size?

\section{Study 1}

Study 1 explores VLS and the breadth of vocabulary knowledge in undergraduates studying in their home country.

\subsection{Methodology}

\subsubsection{Participants}

A total of 49 students (mean age $=23.65$, standard deviation $[S D]=2.445$ ) participated in the study. All students were third year (level six) students in the 
English Department at King Abdulaziz University in Saudi Arabia. Students received approximately $1600 \mathrm{~h}$ of EFL instruction during their public school and university education (Alqurashi, 2013).

\subsubsection{Materials}

VLS questionnaire. The questionnaire we used to gauge students' VLS use was adapted from Alsaif (2011) and based on Schmitt's VLS taxonomy (1997). It contained 37 closed questions. An additional open question that allowed participants to mention additional strategies that they used will not be reported here because no learner mentioned additional learning strategies. All closed questions used the following Likert scale to gauge how often learners used a particular learning strategy: always $=4$, often $=3$, sometimes $=2$, rarely $=1$ and never $=0$.

Following Alsaif (2011), the questionnaire was organised into three sections: (1) strategies used to learn new words, (2) strategies used to consolidate already learned words and (3) general VLS. Each of the learning strategies was categorised as either memory, social, cognitive, metacognitive or determination strategies following Schmitt (1997).

Vocabulary size test. We used Meara and Milton's (2003) vocabulary size test X_Lex (paper-based format; see Milton, 2009) to gauge participants' vocabulary size. This test estimates participants' passive vocabulary knowledge in terms of breadth up to a vocabulary knowledge of 5000 words and has a high level of test validity and reliability (Al-Mutawa, 2013). We used this test as participants' vocabulary knowledge was expected to not exceed 5000 words (e.g., Al-Akloby, 2001; Al-Hazemi, 1993; Alsaif, 2011).

X_Lex is a checklist vocabulary test in which participants place a checkmark next to the words they know. The test consists of six columns with 20 words each (120 words in total), representing the 5000 most frequent words in English. The words were selected from Hindmarsh's (1980) and Nation's (1984) frequency lists (Milton, 2009). The first five columns contain real words that are among the most frequent 5000 words in English. The last column contains non-words or pseudo-words to gauge the amount of guessing by the learners. Vocabulary size scores are calculated as follows: All checkmarks within the first five columns (which contain real words) are added up and this number is multiplied by 50 . Then, all checkmarks in the sixth column (which contains pseudo-words) are added up and multiplied by 250 . Finally, the total number for the sixth column is subtracted from the total number for the first five columns. For example, if the first five columns yield a score of 2500 and the sixth column yields a score of 1000, then the participants' vocabulary size score is 1500 .

\subsubsection{Procedure}

Participants first completed the VLS questionnaire, which was administered in Arabic, the participants' L1. After a short break, participants completed the vocabulary size test. There was no time limit for completion of the questionnaire and vocabulary size test, but all the participants finished within $20 \mathrm{~min}$. 


\subsection{Results}

\subsubsection{Summary Measures}

The results of the X_Lex vocabulary size test showed that participants' estimated mean vocabulary size is 1976 words $(S D=597)$. Estimated vocabulary size ranged from 350 words to 2900 words out of a possible maximum test score of 5000 words. The ratings for individual VLS range from 0.85 (a value between rarely used and never used on the scale) to 2.95 (a value corresponding to often), with a mean rating of 1.98 (a value corresponding to sometimes) out of a maximum score of 4.00 .

\subsubsection{Relationship between VLS and Vocabulary Size}

To determine which VLS contribute significantly to vocabulary size (RQ1), we performed multiple regression analyses, separately for each type of VLS in Schmitt's taxonomy (determination, cognitive, social, memory and metacognitive strategies). All analyses had vocabulary size as the dependent variable and all VLS of the relevant type as independent variables. All independent variables were centred before analysis to minimise collinearity (Belsley, Kuh, \& Welsh, 2005). Independent variables that did not contribute significantly to model fit were removed in a stepwise procedure to yield the final analysis model (Baayen, 2008). Table 1 shows the results from the final statistical models. The only strategy that is significant at the level of $p<0.001$ is guessing the meaning of new words from context. Overall, we can see that most of the strategies that are related to vocabulary size were categorised by Alsaif (2011) as strategies to learn new words (7, 9, 10, 14, 19, and 20) rather than as strategies to consolidate and memorise learned words (21 and 24) or general VLS (32). In addition, the most frequent strategy type in Table 1 is memory strategies $(10,14,19$, and 20$)$.

\subsection{Discussion}

The results revealed that undergraduate participants' receptive vocabulary knowledge is generally poor and would likely not allow learners to perform well in basic communicative tasks and general reading tasks. In addition, participants did not employ many vocabulary learning strategies on a regular basis. However, three of the VLS that positively relate to students' vocabulary size had mean ratings above 2 (i.e., above sometimes) and were thus among those that undergraduates used more frequently. This suggests that some strategies that students were using might have contributed to building their vocabulary knowledge, possibly because use of these strategies might indicate their engagement with English in general. Those findings will be discussed in more detail in the general discussion section.

\section{Study 2}

Study 2 tests VLS and the breadth of vocabulary knowledge in postgraduates living in an L2 environment. 
Table 1. Results from the Multiple Regression Analyses for Undergraduates

\begin{tabular}{|c|c|c|c|c|c|c|}
\hline Strategy type & VLS & Mean $(S D)$ & Estimate & Std. error & $t$-value & $p$-value \\
\hline Determination & $\begin{array}{l}\text { 9. Guessing the } \\
\text { meaning of the } \\
\text { new words from } \\
\text { their contexts }\end{array}$ & $2.35(1.332)$ & 235.75 & 51.86 & 4.545 & $<0.001^{* * *}$ \\
\hline Cognitive & $\begin{array}{l}21 . \text { Writing the } \\
\text { words in a special } \\
\text { vocabulary } \\
\text { notebook }\end{array}$ & $2.27(1.204)$ & 155.28 & 60.39 & 2.571 & $<0.05^{*}$ \\
\hline Social & $\begin{array}{l}\text { 7. Asking the } \\
\text { teacher about } \\
\text { vocabulary } \\
\text { meanings }\end{array}$ & $1.24(1.267)$ & 183.23 & 80.55 & 2.275 & $<0.05^{*}$ \\
\hline \multirow[t]{4}{*}{ Memory } & $\begin{array}{l}\text { 10. Using grammar } \\
\text { cues to guess the } \\
\text { meaning of words }\end{array}$ & $2.27(1.335)$ & 199.36 & 57.97 & 3.439 & $<0.01^{* *}$ \\
\hline & $\begin{array}{l}\text { 14. Writing the } \\
\text { words in full } \\
\text { sentences }\end{array}$ & $1.92(1.367)$ & 156.51 & 52.53 & 2.979 & $<0.01^{* *}$ \\
\hline & $\begin{array}{l}\text { 19. Associating } \\
\text { new words with } \\
\text { known synonyms }\end{array}$ & $0.86(1.225)$ & 212.23 & 68.03 & 3.120 & $<0.01^{* *}$ \\
\hline & $\begin{array}{l}\text { 20. Associating } \\
\text { the new words with } \\
\text { known opposites }\end{array}$ & $2.27(1.204)$ & -178.32 & 72.61 & -2.456 & $<0.05^{*}$ \\
\hline \multirow[t]{2}{*}{ Metacognitive } & $\begin{array}{l}\text { 24. Writing the } \\
\text { words with all the } \\
\text { synonyms known }\end{array}$ & 1.63 (1.185) & 112.65 & 64.07 & 1.758 & $=0.09$ \\
\hline & $\begin{array}{l}\text { 32. Watching } \\
\text { television } \\
\text { programmes }\end{array}$ & $1.53(0.739)$ & 152.66 & 57.70 & 2.646 & $<0.05^{*}$ \\
\hline
\end{tabular}

\subsection{Methodology}

\subsubsection{Participants}

The postgraduate group included 22 male Saudi learners (mean age $=30.50$, $S D=3.051)$ completing their Master's or PhD degrees in different disciplines at Bangor University. These participants have spent between 2 to 7 years in an L2 environment.

\subsubsection{Materials}

VLS questionnaire. We used the same questionnaire as in Study 1 to measure the participants' VLS.

Vocabulary size test. Participants' passive vocabulary size was measured using the XK_Lex vocabulary size test developed by Al-Masrai and Milton (2012; see Al-Masrai, 2009, for validity and reliability information), which captures vocabulary knowledge beyond the 5000 -word limit and is thus appropriate for learners in 
the L2 environment at a higher educational level. Similar to the X_Lex test used in Study 1, the XK_Lex is a paper-and-pencil checklist vocabulary test in which participants place a checkmark next to the words they know. It comprises 100 words representing the 10000 most frequent words of English, divided into 10 columns with 10 words each. The lexical items in the test are taken from Nation (1984) and Kilgarriff (2006). To minimise the effect of guessing, each column of the test also includes two pseudo-words, for a total of 20 pseudo-words. Similar to the X_Lex test in Study 1, vocabulary size scores are calculated by adding up all the real words that received a checkmark and multiplying the sum by 100 . Then, all checked pseudo-words are added up and the sum is multiplied by 500. Participants' vocabulary size score was derived by subtracting the latter sum from the first.

\subsubsection{Procedure}

The procedure was the same as in Study 1.

\subsection{Results}

\subsubsection{Summary Measures}

The XK_Lex test revealed that postgraduates' estimated mean vocabulary size is 5368 words $(S D=1307)$. Vocabulary sizes ranged from 3100 to 8200 words out of a possible maximum test score of 10000 words. Mean VLS ratings ranged from 1.09 (roughly corresponding to rarely on the scale) to 3.41 (a value that is between often and always on the scale), with an overall mean rating of 2.11 (which roughly corresponds to sometimes) out of a maximum rating of 4.00.

\subsubsection{Relationship between VLS and Lexical Knowledge}

We performed multiple regression analyses analogous to the ones in Study 1 to determine which VLS relate significantly to vocabulary size (RQ1) in Saudi postgraduates. Table 2 presents the results from the final statistical models. Again, most VLS strategies that relate to vocabulary size are strategies used to acquire new words $(2,9,11,12,13,19$ and 20) rather than strategies to consolidate and memorise learned words (none) or general VLS (32, 34 and 37). Furthermore, the most common strategy category in Table 2 is again memory strategies $(11,12,13$, 19 and 20). However, three of the five memory strategies which relate to vocabulary size show a negative relationship, such that more use of the strategy relates to a smaller vocabulary. All three of these strategies relate to considering words in isolation rather than in context.

\subsubsection{Comparison of VLS Use between Groups}

In this section, we will highlight VLS that postgraduates use significantly more or less frequently than undergraduates (RQ2). Table 3 lists all VLS for which the mean ratings for undergraduates were significantly or marginally higher than the 
Table 2. Results from the Multiple Regression Analyses for Postgraduates

\begin{tabular}{|c|c|c|c|c|c|c|}
\hline Strategy type & VLS & Mean $(S D)$ & Estimate & Std. error & $t$-value & $p$-value \\
\hline Determination & $\begin{array}{l}\text { 9. Guessing the } \\
\text { meaning of the } \\
\text { new words from } \\
\text { their contexts }\end{array}$ & $2.64(0.790)$ & 883.3 & 343.1 & 2.574 & $<0.05^{*}$ \\
\hline Cognitive & $\begin{array}{l}\text { 2. Reading the } \\
\text { text aloud before } \\
\text { searching for new } \\
\text { words meanings }\end{array}$ & $1.41(0.854)$ & 628.1 & 261.6 & 2.401 & $<0.05^{*}$ \\
\hline Social & $\begin{array}{l}\text { 37. Speaking } \\
\text { English with non- } \\
\text { Arabic speakers } \\
\text { in shops, hospitals, } \\
\text { restaurants, etc. }\end{array}$ & $3.32(1.041)$ & 510.4 & 256.5 & 1.989 & $=0.06$ \\
\hline \multirow[t]{5}{*}{ Memory } & $\begin{array}{l}\text { 11. Visualising the } \\
\text { meaning of the } \\
\text { words }\end{array}$ & $1.86(0.941)$ & 869.2 & 262.0 & 3.317 & $<0.01^{* *}$ \\
\hline & $\begin{array}{l}\text { 12. Saying the } \\
\text { words repeatedly to } \\
\text { learn their sounds }\end{array}$ & 2.59 (1.182) & -422.8 & 194.6 & -2.173 & $<0.05^{*}$ \\
\hline & $\begin{array}{l}\text { 13. Writing the } \\
\text { words alone } \\
\text { repeatedly to learn } \\
\text { their written forms }\end{array}$ & $2.14(0.889)$ & -783.1 & 235.3 & -3.328 & $<0.01^{* *}$ \\
\hline & $\begin{array}{l}\text { 19. Associating } \\
\text { new words with } \\
\text { known synonyms }\end{array}$ & $2.23(1.27)$ & -440.7 & 205.7 & -2.143 & $<0.05^{*}$ \\
\hline & $\begin{array}{l}\text { 20. Associating } \\
\text { the new words with } \\
\text { known opposites }\end{array}$ & $2.23(1.11)$ & 752.5 & 255.6 & 2.944 & $<0.01^{* *}$ \\
\hline \multirow[t]{2}{*}{ Metacognitive } & $\begin{array}{l}\text { 32. Watching } \\
\text { television } \\
\text { programmes }\end{array}$ & $3.44(0.590)$ & 650.3 & 218.2 & 2.981 & $<0.01^{* *}$ \\
\hline & $\begin{array}{l}\text { 34. Reading } \\
\text { newspapers or } \\
\text { magazines }\end{array}$ & $2.41(0.908)$ & 601.8 & 261.9 & 2.298 & $<0.05^{\star}$ \\
\hline
\end{tabular}

Table 3. Vocabulary Learning Strategies for Which Mean Ratings for Undergraduates Were Significantly or Marginally Higher than Mean Ratings for Postgraduates

\begin{tabular}{|c|c|c|c|}
\hline$\overline{\text { VLS }}$ & $\begin{array}{c}\text { Mean scores }(S D) \\
\text { undergraduates }\end{array}$ & $\begin{array}{c}\text { Mean scores }(S D) \\
\text { postgraduates }\end{array}$ & $t$-test \\
\hline $\begin{array}{l}\text { 7. Asking the teacher about their } \\
\text { meanings }\end{array}$ & $2.86(0.979)$ & $1.59(0.959)$ & $\begin{array}{l}t=-5.1113 \\
p<0.001^{* * *}\end{array}$ \\
\hline $\begin{array}{l}\text { 16. Volunteering to say the words } \\
\text { loudly in class if the teacher asks }\end{array}$ & $2.24(1.217)$ & $1.50(1.225)$ & $\begin{array}{l}t=-2.3747 \\
p=0.09\end{array}$ \\
\hline $\begin{array}{l}\text { 25. Writing the words with all the } \\
\text { opposites I know }\end{array}$ & $1.67(1.144)$ & $1.09(0.921)$ & $\begin{array}{l}t=-2.2805 \\
p=0.1\end{array}$ \\
\hline
\end{tabular}


mean ratings for postgraduates. Two-tailed $t$-tests with $p$-values adjusted for multiple comparisons with a false discovery rate correction (Benjamini \& Hochberg, 1995) showed that only one strategy was used significantly, and a further two marginally more frequently, by undergraduates compared to postgraduates, reflecting the infrequent use of VLS in general among undergraduate participants. Notably, two of the strategies that undergraduates used more frequently than postgraduates are social strategies involving simple classroom interaction (7 and 16). All strategies were relatively simple and focused on the word in isolation rather than in context.

In contrast, Table 4 lists all VLS for which the mean ratings for postgraduates were significantly or marginally higher than the mean ratings for undergraduates. Two-tailed $t$-tests with $p$-values adjusted using a false discovery correction showed that seven strategies were used significantly or marginally more frequently by postgraduates compared to undergraduates. Notably, all but two of these strategies serve to consolidate and memorise already learned words. Moreover, postgraduates use strategies that allow them to process words in their sentential and conversational contexts $(2,34,35,36$ and 37$)$ more frequently than undergraduates. Finally, some of the strategies that postgraduates use more frequently than undergraduates are related to living in an L2 environment and the opportunities to engage with the L2 that go along with this (36, 37 and possibly 34,35$)$.

\subsubsection{Individual Differences}

This section focuses on individual learner styles (RQ3) using cluster analysis. This procedure allows us to group participants with similar VLS profiles and

Table 4. Vocabulary Learning Strategies for which Mean Ratings for Postgraduates were Significantly or Marginally Higher than Mean Ratings for Undergraduates

\begin{tabular}{|c|c|c|c|}
\hline VLS & $\begin{array}{l}\text { Mean scores }(S D) \\
\text { undergraduates }\end{array}$ & $\begin{array}{c}\text { Mean scores }(S D) \\
\text { postgraduates }\end{array}$ & $t$-test \\
\hline \multirow{2}{*}{$\begin{array}{l}\text { 2. Reading the whole text aloud } \\
\text { before searching for the meaning of } \\
\text { the new words }\end{array}$} & \multirow[t]{2}{*}{$1.57(1.323)$} & \multirow[t]{2}{*}{$2.27(0.985)$} & $t=2.4827$ \\
\hline & & & $p=0.08$ \\
\hline \multirow[t]{2}{*}{ 6. Using English/English dictionary } & \multirow[t]{2}{*}{$1.24(1.269)$} & \multirow[t]{2}{*}{$2.41(1.221)$} & $t=3.6714$ \\
\hline & & & $p<0.01^{* *}$ \\
\hline \multirow{2}{*}{$\begin{array}{l}\text { 31. Connecting the English words with } \\
\text { other words in English which have the } \\
\text { same sound, like meat and meet, etc. }\end{array}$} & \multirow[t]{2}{*}{$1.53(0.737)$} & \multirow[t]{2}{*}{$2.59(1.141)$} & $t=3.9998$ \\
\hline & & & $p<0.01^{* *}$ \\
\hline \multirow{2}{*}{$\begin{array}{l}\text { 34. Reading newspapers or } \\
\text { magazines }\end{array}$} & \multirow[t]{2}{*}{$1.55(1.276)$} & \multirow[t]{2}{*}{$2.41(0.908)$} & $t=3.2271$ \\
\hline & & & $p<0.05^{*}$ \\
\hline \multirow[t]{2}{*}{ 35. Reading stories or novels } & \multirow[t]{2}{*}{$1.41(1.257)$} & \multirow[t]{2}{*}{$2.14(1.167)$} & $t=2.3735$ \\
\hline & & & $p=0.09$ \\
\hline \multirow{2}{*}{$\begin{array}{l}\text { 36. Speaking English with my friends } \\
\text { inside or outside school }\end{array}$} & \multirow[t]{2}{*}{$1.57(1.258)$} & \multirow[t]{2}{*}{$2.64(1.002)$} & $t=3.814$ \\
\hline & & & $p<0.01^{* *}$ \\
\hline \multirow{2}{*}{$\begin{array}{l}\text { 37. Speaking English with non- } \\
\text { Arabic speakers in shops, hospitals, } \\
\text { restaurants, etc. }\end{array}$} & \multirow[t]{2}{*}{$2.53(1.386)$} & \multirow[t]{2}{*}{$3.32(1.041)$} & $t=2.6475$ \\
\hline & & & $p=0.07$ \\
\hline
\end{tabular}


has the ability to uncover different learner styles. We used a K-means clustering approach, an unsupervised machine learning algorithm that identifies a predetermined number of groups in the data. One issue with this approach is to determine the right number of clusters $(K)$ for the analysis. We did this using the NbClust package in R (Charrad, Ghazzali, Boiteau, \& Niknafs, 2014). The NbClust function uses 30 different approaches for finding the optimal number of clusters in a data set and determines which number of clusters is considered optimal in the largest number of approaches. The optimal number of clusters was 2 . Inspection of the groups suggests that the first cluster represents learners with infrequent VLS usage overall (24 undergraduates and 10 postgraduates). The second cluster includes learners with frequent VLS usage overall (25 undergraduates and 12 postgraduates). In particular, the mean usage ratings for all VLS were numerically lower and the mean usage ratings for 26 of the 37 VLS were statistically significantly lower (Welch two-sample $t$-tests with $p$-values adjusted with a false discovery rate correction, all $t>2$, all $p<0.05$ ) for participants in the first cluster than for participants in the second cluster.

Next, a linear regression model tested whether the level of education and the VLS profile (as established through the cluster analysis) relate to vocabulary size. The model included level of education (undergraduate vs. postgraduate), the VLS profile (low vs. high VLS use) and their interaction as independent variables and vocabulary size as dependent variable. The interaction did not significantly contribute to model fit and was removed. The results show a significant main effect for both level of education (estimate $=-3375.2$, std. error $=213.7, t=-15.478$, $p<0.001^{* * *}$ ) and VLS profile (estimate $=-496.9$, std. error $=197.8, t=-2.102, p<$ $\left.0.05^{*}\right)$. This suggests that using more VLS in general is related to larger vocabulary size independently of level of education.

\subsection{Discussion}

Results from Study 2 indicated that Saudi postgraduates' vocabulary size is considerably higher than that of undergraduates. Postgraduate vocabulary size showed significant relationships with several strategies that involve considering words in their sentential and conversational context. In addition, VLS used more frequently by undergraduates tended to focus on words in isolation and simple classroom interactions, whereas VLS used more frequently by postgraduates tended to focus on words in their sentential and discourse contexts. Finally, we determined two groups of learners which differed in their overall use of VLS rather than in preferring certain VLS over others. These findings are discussed in more detail in the next section.

\section{General Discussion}

\subsection{Participants' Vocabulary Size}

The findings of this study indicate that undergraduates' and postgraduates' vocabulary sizes are comparable to findings from previous studies that measured Saudi students' vocabulary size (e.g., Al-Akloby, 2001; Al-Hazemi, 1993; 
Al Qahtani, 2005; Alsaif, 2011; Masrai, 2015). None of the undergraduates met the suggested vocabulary thresholds for performing well in basic communication, general reading comprehension, reading academic or authentic texts, comprehending authentic materials or understanding spoken discourse (Al-Masrai \& Milton, 2012; Hirsh \& Nation, 1992; Laufer, 1997; Milton, 2009; Nation, 2006). All postgraduates met the threshold for general reading comprehension and performing well in basic communication (Laufer, 1997; Milton, 2009). In addition, a majority of postgraduates met Hirsh and Nation's (1992) suggested thresholds for reading academic and authentic texts, reflecting that their vocabulary knowledge is adequate. Our results support Fu's (2005) argument that lexical attainment is often problematic for many L2 students, even for advanced learners.

Previous studies have linked the low vocabulary size among Saudi students to the late beginning of English instruction within Saudi public schools (grade 4, 10 years old), the classroom environment, instructional approaches, teachers' experience, word difficulty variables and morphological processing (Alsaif, 2011; Masrai, 2016; Masrai \& Milton, 2015). The results from the current studies suggest that the infrequent use of VLS may relate to Saudi undergraduates' low vocabulary uptake. The results also suggest that undergraduates may benefit from quite simple and easily implemented VLS, such as asking about a word's meaning in class. However, students may not always be aware of the benefits of such simple strategies. EFL instructors could therefore emphasise the importance of VLS to students or provide students with a repertoire of VLS that are relevant for their level of knowledge and that students can draw from when learning vocabulary.

\subsection{Relationship between VLS Use and Lexical Knowledge}

Our first research question (RQ1) explored which VLS relate positively and significantly to vocabulary size in both groups. These strategies are guessing the meaning of words from context, and watching television programmes. Notably, the strategy of guessing the meaning from context related to vocabulary size in both groups and was the only VLS that was significant at the $p<0.001$ level in the undergraduate group. This finding supports previous studies, which also found significant relationships of this VLS and vocabulary size (e.g., Al Qahtani, 2005; Alsaif, 2011). Since guessing the meaning of words from context relates to vocabulary size in several studies, it is worth exploring whether using this strategy increases one's vocabulary size or whether participants with larger vocabulary sizes simply have more opportunities to use this strategy. In order to guess the meaning of words from context, learners need to have adequate knowledge about the vocabulary and grammatical structures in the context. Furthermore, the more words, grammatical structures and sentences in context learners understand, the easier it becomes for them to guess an individual unknown word from the context. Lexical inferencing strategies are also useful as test-taking strategies when using a dictionary is not an option. Thus, students with substantial English testtaking experience may be more effective users of this particular strategy. Even when dictionary use is an option, being able to guess the meaning of words from context, although possibly more error prone, is more time-efficient than looking up words in a dictionary. If this is the case, then learners with larger vocabularies

Vocabulary Learning and Instruction, 7 (1), 14-34. 
and more confidence to guess correctly may simply choose to employ this more time-efficient strategy more often than learners with smaller vocabularies. Alternatively, using this strategy may actually benefit vocabulary acquisition. In particular, in order to successfully guess the meaning of a word from context, the learner needs to engage with the material in depth (Ellis, 1995; Hulstijn, 2001). This involves engagement such as determining the meaning of surrounding words, the grammatical structures and thematic roles of the surrounding sentences, the topic and broader context of the text. Such deep engagement with the text may actively increase learners' vocabulary knowledge, possibly by strengthening associative bonds between words (Richards, 1976). However, previous studies on this topic have found inconclusive results: While Shangarfam, Ghorbani, Safarpoor and Maha (2013) found an advantage for guessing word meaning over looking words up, Mondria (2003) did not.

Interestingly, another VLS which positively related to vocabulary knowledge in both groups is watching television programmes. This strategy actually requires learners to guess unknown words from context, as speech in television programmes is typically too fast to allow looking up vocabulary. In addition, it is possible that only students with sufficient confidence in their lexical inferencing ability attempt to watch English-language television. Overall, our results support a connection between guessing strategies and vocabulary size; however, more studies with larger sample sizes, especially at the postgraduate level, are needed to determine whether these strategies increase learners' vocabulary knowledge.

It is also noteworthy that three of the memory strategies in the postgraduate group related negatively to vocabulary size. All of these strategies involved basic strategies that relate to words in isolation rather than in context, such as saying words repeatedly to learn their sounds or writing words repeatedly to learn their written forms. It is very unlikely that using such strategies would decrease learners' vocabulary size. Rather it seems that learners with smaller vocabulary sizes to begin with may select these strategies more frequently than learners who already have larger vocabularies.

Our results also suggest that the interrelationship between vocabulary acquisition and VLS use might be more sophisticated than what is reported in the literature. In particular, only two strategies showed reliable positive relationships with vocabulary size in both groups of students. This suggests that there are some strategies which may be beneficial for certain learner groups or learners of certain proficiency levels, but not for others. In line with Alsaif (2011) and Alqurashi (2013), the most frequent type of strategy that related to learners' vocabulary size in the current study was memory strategies. However, not all memory strategies related positively to vocabulary size, with some of the more basic memory strategies associated with learners with small vocabularies. Contrary to results from Hamzah et al. (2009) and Tanyer \& Ozturk (2014), only one social strategy in each group related to learners' vocabulary size. This suggests that the undergraduates, and even some postgraduates, in the current study focused on and may have benefited from strategies that encourage rote learning and memorisation. Further studies with larger sample sizes are needed to determine which strategies may potentially be beneficial for which learner groups. 


\subsection{Comparison of VLS Use across Groups}

RQ2 focused on strategies which postgraduates use significantly more or less frequently than undergraduates. The current results revealed that undergraduates only used three strategies significantly or marginally more often than postgraduates. Moreover, all of the VLS are simple strategies that consider words in isolation and represent strategies that are typically part of the normal routine in the EFL classroom and thus represent expected classroom behaviour, such as volunteering to say words aloud in class or asking the teacher about a word's meaning. In contrast, postgraduates take advanced content classes in their field of study with little opportunity to volunteer to say words aloud in the class. In addition, students may consider asking the teacher about a word's meaning inappropriate in advanced content-based classes. This highlights that the learning environment in the classroom may be more or less conducive to the use of certain VLS. In addition, there is no evidence that undergraduates used any VLS that are more complex or occur outside of the classroom more frequently than postgraduates.

Postgraduates used seven strategies reliably or marginally more frequently than undergraduates. Again, some of these strategies seem to be related to postgraduates' current learning environment. As students in an L2 environment, postgraduates have ample opportunity to interact with native English speakers and other international students in English. Postgraduates also make use of advanced metacognitive and social strategies, such as reading newspapers or magazines and stories or novels or interacting with speakers in English inside and outside of the classroom. This suggests that postgraduates are actively engaging with authentic English language materials and English language speakers, which are more readily available in the L2 environment compared to the L1 environment of the undergraduates. In addition, postgraduates are more likely to use VLS outside of the classroom environment.

\subsection{Individual Differences}

We used cluster analysis to explore whether there were any distinct VLS profiles or learning styles (RQ3). Cluster analysis determined two VLS usage profiles: overall infrequent VLS usage and overall frequent VLS usage. We thus found no evidence for different types of learner styles, such as visual learners compared to auditory learners, a preference for speaking compared to listening, or a preference for social compared to memory strategies, when it comes to VLS. Our results thus do not support the claim that individual learner profiles "might do more justice to the individuality of the language learner" (Skehan, 1986, p. 82). These results also suggest that asking instructors to cater to individual vocabulary learner styles may not be warranted, an argument which is in line with that of Pashler et al. (2008). However, it may also be the case that the learners do have individual learner styles, but do not have sufficient awareness of their needs as a learner to select VLS that work well for their particular learner style. We did, however, find that participants who reported using VLS more frequently overall had significantly larger vocabulary sizes and that this effect occurred in addition to

Vocabulary Learning and Instruction, 7 (1), 14-34. 
whether they were undergraduates or postgraduates. This finding is in line with that of Sanaoui (1992) and Kojic-Sabo and Lightbown (1999), who concluded that frequent and elaborate usage of VLS was related to high achievement levels. Gu \& Johnson (1996) also contended that both learners' vocabulary knowledge and language proficiency appear to be related to certain learning aspects, such as learners' motivation in language acquisition, the ability to use dictionaries and the willingness to spend additional time on practicing novel acquired lexical items. However, our findings contrast with that of Lessard-Clouston (1996), who did not find any relationship between frequent usage of VLS and language learning success. It is thus possible that both the quantity and quality of VLS are involved in language learning success, and that quantity alone may not necessarily relate to higher success in language learning.

Overall, the results of our study suggest that VLS usage in general positively relates to vocabulary size. It seems that learners who show greater engagement with VLS overall also have larger vocabularies, irrespective of educational level. Again, the directionality of this result is not clear. It is possible that engagement with the learning process through the frequent use of VLS might lead to larger vocabulary sizes (e.g., Hamzah et al., 2009; Tanyer \& Ozturk, 2014). However, another possibility is that learners who already have larger vocabularies have more means to engage with VLS, especially those that require a certain vocabulary base, such as reading newspapers, interacting with other speakers outside of the classroom, etc.

\section{Conclusion}

This study highlighted the VLS use of students in higher education and the relationship of VLS with students' breadth of vocabulary knowledge. The results showed that postgraduates had overall larger vocabulary sizes and used more strategies that considered lexical items in their sentence and discourse contexts than undergraduates. The strategies of guessing the meaning of words from context and watching television programmes stood out among the VLS because they related positively to vocabulary size in both groups. Cluster analysis provided two VLS usage profiles which differed in the frequency of VLS use overall rather than in terms of individual learner styles. Frequency of VLS use and educational level were found to be independently related to learners' vocabulary size. The results tentatively suggest that VLS use overall should be encouraged in the EFL classroom, that guessing strategies may possibly contribute to vocabulary size in both undergraduates and postgraduates, and that students may not differ enough in terms of their learning styles to justify asking teachers to cater to individual learning styles.

\section{Acknowledgements}

The first author (Alaa Alahmadi) is immensely grateful to Dr. Ahmed Al-Masrai, Mr. Osama Alruwaili and Mr. Mohammed Hakami for their assistance and support during data collection. 


\section{References}

Al-Akloby, S. (2001). Teaching and learning English vocabulary in Saudi Arabian public schools: An exploratory study of some possible reasons behind students' failure to learn English vocabulary. Unpublished PhD thesis, University of Essex.

Al-Hazemi, H. (1993). Low level EFL vocabulary tests for Arabic speakers. Unpublished PhD thesis, University of Wales, Swansea.

Al-Masrai, A. (2009). Measuring the English vocabulary size of Saudi university students: Validating a new 10,000 word vocabulary size test. Unpublished Master dissertation, Swansea University, Swansea, UK.

Al-Masrai, A., \& Milton, J. (2012). The vocabulary knowledge of University Students in Saudi Arabia. Perspectives (TESOL Arabia), 19(3), 13-19.

Al-Mutawa, Y. (2013). Estimating the EFL vocabulary size of learners in school and university in Saudi Arabia: Validity of $X_{-}$Lex vocabulary size test. Unpublished MA thesis, Swansea University.

Al Qahtani, M. (2005). The use of vocabulary learning strategies by EFL learners at three different educational levels. Unpublished PhD thesis, Essex University.

Alqurashi, N. (2013). Vocabulary learning strategies of Saudi undergraduate EFL students at Taif University and its relation to their vocabulary size. Unpublished MA dissertation, Anglia Ruskin University, Cambridge, UK.

Alsaif, A. (2011). Investigating vocabulary input and explaining vocabulary uptake among EFL learners in Saudi Arabia. Unpublished PhD thesis, Swansea University, Swansea, UK.

Baayen, R. H. (2008). Analyzing linguistic data: A practical introduction to statistics using $R$. Cambridge: Cambridge University Press.

Belsley, D. A., Kuh, E., \& Welsch, R. E. (2005). Regression diagnostics: Identifying influential data and sources of collinearity (Vol. 571). Hoboken, New Jersey: John Wiley \& Sons.

Benjamini, Y., \& Hochberg, Y. (1995). Controlling the false discovery rate: A practical and powerful approach to multiple testing. Journal of the Royal Statistical Society. Series B (Methodological), 57(1), 289-300.

Catalan, R. (2003). Sex differences in L2 vocabulary learning strategies. Applied Linguistics, 13(1), 54-77. doi: 10.1111/1473-4192.00037.

Chamot, A. U., \& O’Malley, M. (1987). The cognitive academic language learning approach: A Bridge to the mainstream. TESOL Quarterly, 21(2), 227-250. doi: $10.2307 / 3586733$.

Charrad, M., Ghazzali, N., Boiteau, V., \& Niknafs, A. (2014). NbClust: An R package for determining the relevant number of clusters in a data set. Journal of Statistical Software, 61(6), 1-36. Retrieved from http://www. jstatsoft.org/v61/i06/

Coady, J. (1997). L2 vocabulary acquisition: A synthesis of the research. In J. Coady \& T. Huckin (Eds.), Second language vocabulary acquisition (pp. 273-290). Cambridge: Cambridge University Press. 
Cohen, A. D. (1998). Strategies in using and learning a second language. Essex: Addison Wesley.

Cook, L. \& Mayer, R. (1983). Reading strategies training for meaningful learning from prose. In M. Pressley \& J. Levin (Eds.), Cognitive Strategy Research: Educational Applications, pp. 87-131. New York: Springer-Verlag.

Ellis, N. C. (1995). The psychology of foreign language vocabulary acquisition: Implications for CALL. Computer Assisted Language Learning, 8, 103-128. doi: 10.1080/0958822940080202.

Fillmore, L. W. (1983). The language learner as an individual: Implications of research on individual differences for the ESL teacher. On TESOL, 82, 157-173.

$\mathrm{Fu}, \mathrm{I}$. (2005). Students approaches to learning Chinese vocabulary. Unpublished PhD thesis, Virginia Polytechnic Institute and State University, Blacksburg, VA.

Gu, Y. \& Johnson, R. (1996). Vocabulary learning strategies and language learning outcomes. Language Learning, 46(4), 643-679. doi: 10.1111/j.1467-1770.1996. tb01355.x.

Gu, Y. (2003). Vocabulary learning in second language: Person, task, context and strategies. Electronic Journal. TESL-EJ, 7(2), 1-26.

Hamzah, M. S. G., Kafipour, R., \& Abdullah, S. K. (2009). Vocabulary learning strategies of Iranian undergraduate EFL students and its relation to their vocabulary size. European Journal of Social Sciences, 11(1), 39-50.

Hindmarsh, R. (1980). Cambridge English Lexicon. Cambridge: Cambridge University Press.

Hirsh, D., \& Nation, P. (1992). What vocabulary size is needed to read unsimplified texts for pleasure? Reading in a Foreign Language, 8(2), 689-696.

Hulstijn, J. H. (2001). Intentional and incidental vocabulary learning: A reappraisal of elaboration, rehearsal, and automaticity. In P. Robinson (ed.), Cognition and second language instruction (pp. 258-286). New York: Cambridge University Press.

Kilgarriff, A. (2006). BNC database and word frequency lists. Retrieved from http:// www.kilgarriff.co.uk/bnc-readme.html\#lemmatised

Koizumi, R., \& In'nami, Y. (2013). Vocabulary knowledge and speaking proficiency among second language learners from novice to intermediate levels. Journal of Language Teaching and Research, 4(5), 900-913. doi: 10.4304/ jltr.4.5.900-913.

Kojic-Sabo, I., \& Lightbown, P. (1999). Students' approaches to vocabulary learning and their relationship to success. The Modern Language Journal, 83(2), 176-192. doi: 10.1111/0026-7902.00014.

Kolb, D. A. (1984). Experiential learning. Englewood Cliffs, NJ: Prentice-Hall.

Kolb, D.A. (1985). Learning style inventory. Boston, MA: McBer.

Kozhevnikov, M. (2007). Cognitive styles in the context of modern psychology: Toward an integrated framework of cognitive style. Psychological Bulletin, 133, 464-481. doi: 10.1037/0033-2909.133.3.464. 
Laufer, B. (1997). What's in a word that makes it hard or easy? Intralexical factors affecting the difficulty of vocabulary acquisition. In M. McCarthy \& N. Schmitt (Eds.), Vocabulary description, acquisition and pedagogy (pp. 140-155). Cambridge: Cambridge University Press.

Laufer, B. (1994). The lexical profile of second language writing: Does it change over time? RELC Journal, 25(2), 21-33. doi: 10.1177/003368829402500202.

Lessard-Clouston, M. (1996). ESL vocabulary learning in a TOEFL preparation class: A case study. Canadian Modern Language Review, 53, 97-119. doi: 10.3138/cmlr.53.1.97.

Masrai, A. M. (2015). Investigating and Explaining the Relationship between L1 Mental Lexicon Size and Organisation and L2 Vocabulary Development. Unpublished PhD Thesis, Swansea University, Swansea.

Masrai, A. M., \& Milton, J. (2015). An investigation of the relationship between L1 lexical translation equivalence and L2 vocabulary acquisition. International Journal of English Linguistics, 5(2), 1-7. doi: 10.5539/ijel.v5n2p1.

Masrai, A. M. (2016). The influence of morphological knowledge on lexical processing and acquisition: The case of Arab EFL learners. Ampersand, 3, 52-60.

McCarthy, M. (1990). Vocabulary. Oxford: Oxford University Press.

McCarthy, M. (2001). An interview with Professor Michael McCarthy. Cambridge Connection, 2(1). Hong Kong: China.

Meara, P. \& Jones, G. (1988). Vocabulary size as a placement indicator. In P. Grunwell (eds.) Applied Linguistics in Society. London: Centre for Information on Language Teaching and Research, vol. 24, no. 4, pp. 80-87.

Meara, P. \& Milton, J. (2003) X_Lex, The Swansea Levels Test. Newbury: Express.

Milton, J. (2009). Measuring second language vocabulary acquisition. Bristol: Multilingual Matters.

Mondria, J. A. (2003). The effects of inferring, verifying and memorising on the retention of L2 word meanings. Studies in Second Language Acquisition, 25, 473-499.

Nation, I. S. P. (1984). Vocabulary lists: Words, affixes and stems. English University of Wellington, New Zealand: English Language Institute.

Nation, I. S. P. (1990). Teaching and learning vocabulary. Boston, MA: Heinle \& Heinle Publishers.

Nation, I. S. P. (2001). Learning vocabulary in another language. Cambridge: Cambridge University Press.

Nation, I. S. P. (2006). How large a vocabulary is needed for reading and listening? The Canadian Modern Language Review, 63, 59-82.

O’Malley, J. \& Chamot, A. (1990). Learning strategies in second language acquisition. Cambridge: Cambridge University Press.

Ormrod, J. E. (2008). Educational psychology: Developing learners (6th ed.). Upper Saddle River, NJ: Pearson. 
Oxford, R. L. (1990). Language learning strategies: What every teacher should know. Englewood Cliffs, NJ: Newbury House.

Oxford, R. L. (2003). Language learning styles and strategies: An overview. GALA. Retrieved from http://web.ntpu.edu.tw/ language/workshop/read2.pdf

Pashler, H., McDaniel, M., Rohrer, D., \& Bjork, R. (2008). Learning styles: Concepts and evidence. Psychological Science in the Public Interest, 9(3), 105-119. doi: 10.1111/j.1539-6053.2009.01038.x.

Read, J. (1997). Vocabulary and testing. In N. Schmitt \& M. McCarthy (eds.), Vocabulary description, acquisition, and pedagogy. Cambridge: Cambridge University Press.

Richards, J. C. (1976). The role of vocabulary teaching. TESOL Quarterly, 10, 77-89. doi: 10.2307/3585941.

Ruutmets, K. (2005). Vocabulary learning strategies in studying English as a foreign language. Master's thesis. Retrieved from http://www.utlib.ee/ekollect/diss/ mag/2005/b17557100/ruutmets.pdf

Safian, N. H., Malakar, S., \& Kalajahi, S. A. R. (2014). Exploring vocabulary learning strategies used by UPM TESL undergraduates. Advances in Language and Literary Studies, 5(5), 1-4.

Sanaoui, R. (1992). Vocabulary learning and teaching in French as a second language classrooms. Unpublished PhD Thesis, University of Toronto, Canada.

Schmitt, N. (1997). Vocabulary learning strategies. In N. Schmitt, and M. McCarthy, M. (eds.) Vocabulary: Descriptive, Acquisition and Pedagogy, pp. 199-227. Cambridge: Cambridge University Press.

Schmitt, N. (2000). Vocabulary in language teaching. Cambridge: Cambridge University Press.

Shangarfam, N., Ghorbani, N., Safarpoor, E., \& Maha, M. (2013). The comparative impact of lexical translation and lexical inferencing on EFL learners' vocabulary retention. Management Science Letters, 3(12), 2889-2908.

Shen, Z. (2008). The roles of depth and breadth of vocabulary knowledge in EFL reading performance. Asian Social Science, 4, 135-137.

Skehan, P. (1986). Cluster analysis and the identification of learner types. In V. Cook (Ed.), Experimental mental approaches to second language acquisition, (pp. 81-94). Oxford: Pergamon.

Sternberg, R. J., Grigorenko, E. L., \& Zhang, L. (2008). Styles of learning and thinking matter in instruction and assessment. Perspectives on Psychological Science, 3, 486-506. doi: 10.1111/j.1745-6924.2008.00095.x.

Stern, H. (1975). What can we learn from the good language learner? Canadian Modern Language Review, 31(304), 318.

Stæhr, L. S. (2008). Vocabulary size and the skills of listening, reading and writing. Language Learning, 36, 139-152. doi: 10.1080/09571730802389975.

Stæhr, L. S. (2009). Vocabulary knowledge and advanced listening comprehension in English as a foreign language. Studies in Second Language Acquisition, 31(04), 577-607. 
Stoffer, I. (1995). University foreign language students' choice of vocabulary learning strategies as related to individual difference variables. Unpublished Doctoral Dissertation, University of Alabama.

Tanyer, S. \& Ozturk, Y. (2014). Pre-service English Teachers' vocabulary learning strategy use and vocabulary size: A cross-sectional evaluation. Journal of Language Teaching and Research, 5(1), 37-45. doi: 10.4304/j1tr.5.1.37-45.

Wenden, A. L. (1982). Learner strategies. TESOL Newsletter, 19(5), 1-7.

Wilkins, D. (1972). Linguistics and language teaching. London: Edward Arnold. 